\title{
The improvement of adhesion between epoxy coating and metal matrix through plasma treatment
}

\author{
Z. Zhai ${ }^{1}$; L.J. Feng ${ }^{1,2^{\star}}$, Q. Hou $^{1,2}$, A.L. Lei ${ }^{1,2}$ \\ ${ }^{1}$ School of Materials Science and Engineering, Xi'an University of Technology, China \\ ${ }^{2}$ Key Lab. Of Corrosion and Protection Of Shannxi Province, Xi'an China \\ *englajun@xaut.edu.cn
}

Keywords: low-temperature plasma, epoxy coatings, Q235 steels, adhesion strength

\begin{abstract}
In this work, the surface of Q235 steels was treated by air plasma to improve the adhesion between epoxy coatings and Q235 steels. The epoxy coatings were prepared through the electrostatic spraying. The disbonding test was used to characterized the adhesion strength of epoxy coatings. Meanwhile, the chemical and physical properties of Q235 steels matrix surface before and after treatment were investigated using XPS, AFM and FTIR. The results showed that both the surface roughness and surface free energy of Q235 steels have an obvious increase after the air plasma treatment. In addition, some polar groups were introduced on the surface of matrix. The adhesion strength of epoxy coatings was enhanced from $1.67 \pm 0.48 \mathrm{MPa}$ to $4.25 \pm 0.58 \mathrm{MPa}$.
\end{abstract}

\section{Introduction}

In this paper a new optimal design of soccer robot control system which is based on mechanical analyses and calculations on the pressure and transmutation states of chip kick mechanics, this new control system with high precision for speed control and high dynamic quality.

Due to excellent mechanical properties and high corrosion resistance, the epoxy coating was wildly applied to petroleum pipelines, ships and other devices surface to prevent them from being corroded $[1,2]$. However, local shedding were often occurred due to poor adhesion, which weakened the protective ability of coatings on steel [3,4]. In serious cases, corrosion occurred on metallic substrate[5,6]. Currently, Sand blast is the common method for surface treatment to improve the roughness of matrix surface and thus enhance the adhesion strength between coatings and matrix [7]. As we all known that the sand blast improves the adhesion strength only by improving the physical bonding of the adhesion. Air plasma treatment has easy operation and wide ranges of raw materials [8,9]. In addition, during air plasma treatment, large amounts of oxygen, nitrogen active groups will be produced. Those active groups with high energy can enhance the surfactivity and surface free energy of substrates, in turn, raise the adhesion strength between epoxy coatings and metal matrix. In this work, the surface of Q235 steels was treated by air plasma and epoxy coatings were prepared by electrostatic spraying. This work can provide a reference for further experimental research and application.

\section{Materials and methods}

\subsection{Material}

The Q235 steel has nominal compositions as following (wt.\%): C 0.220, Mn 0.480, Si 0.022, P 0.012, and Fe as balance. The epoxy powder (CYD-014U) was supplied by China Petroleum \& Chemical Corporation.

\subsection{Metal surface treatment and coating preparation}

A plasma torch (PM-V82, Shenzhen Fang Rui Technology Co., Ltd, China) was used to treat the surface of Q235 steels at room temperature. Before treatment, the steel matrix was immersed in ethyl alcohol solution for ultrasonics cleaning about $3 \mathrm{~min}$, and then was blow-dried with cold wind. 
The epoxy coatings were prepared on the steel matrix by A NewKCl-CU801 electrostatic spraying equipment, and parameters were set like this: pressure of compressed air was 0.4-0.7 MPa; the voltage was 50-60 KV; the distance between spray gun and specimen was $100-50 \mathrm{~mm}$.

\subsection{Disbonding test}

In this test, Q235 steel wire with a diameter of $2 \mathrm{~mm}$ was chosen as the matrix, then cut into sections with $6 \mathrm{~cm}$ in length. For each section, coatings with $5 \mathrm{~cm}$ lengths was prepared on it. A XWW-20A universal testing machine was used to test adhesion strength. The displacement rate was $2 \mathrm{~mm} / \mathrm{min}$. Figure 1 is the installation diagram of disbonding test. As the Figure 1 shows, the steel wire with $5 \mathrm{~cm}$ lengths coatings was loaded through a corresponding round hole of steel sheet to induce a shear between coatings and the steel. The diameter of this hole is $2+0.02 \mathrm{~mm}$. The load increased until coatings was completely exfoliated, and the maximum value $F$ was determined simultaneously. The adhesion of coatings can be calculated, according to the following equation:

$$
\sigma=F / A
$$

Where $A$ is the area of coatings $\left(\mathrm{mm}^{2}\right) . F$ is the maximum value for disbonding $(\mathrm{N}) . \sigma$ is the adhesion strength between coatings and steel matrix. 20 specimens were tested for each treated sample, then, the averages were obtained. Each specimen repeated 20 times.

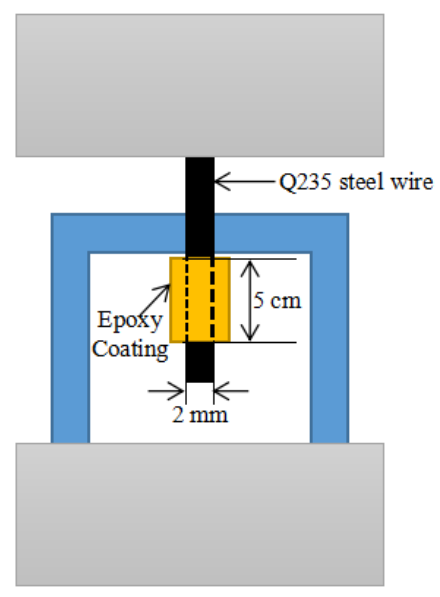

Table 1. Testing liquids and their surface tension components.

\begin{tabular}{cccc}
\hline \multirow{2}{*}{ Testing liquids } & \multicolumn{3}{c}{ Surface tension $\left(\mathrm{mJ} / \mathrm{m}^{2}\right)$} \\
& $\gamma_{\mathrm{L}}^{\mathrm{p}}$ & $\gamma_{\mathrm{L}}^{\mathrm{d}}$ & $\gamma_{\mathrm{L}}$ \\
\hline Water $\left(\mathrm{H}_{2} \mathrm{O}\right)$ & 51.0 & 21.8 & 72.8 \\
Diiodomethane $\left(\mathrm{CH}_{2} \mathrm{I}_{2}\right)$ & 2.3 & 48.5 & 50.8 \\
\hline
\end{tabular}

Figure 1. The installation diagram of disbonding test.

\subsection{Surface free energy}

An optical contact angle measuring device was used to test the contact angles of Q235 steels to calculate surface free energy. Testing liquids were water (polar solvent) and diiodomethane (non-polar solvent). The surface tension components of testing liquids are shown in Table 1 . The equations of surface free energy are listed as follow:

$$
\begin{gathered}
\gamma_{\mathrm{L}}(1+\cos \theta)=2 \sqrt{\gamma_{\mathrm{S}}^{p} \gamma_{\mathrm{L}}^{p}}+2 \sqrt{\gamma_{\mathrm{S}}^{d} \gamma_{\mathrm{L}}^{d}} \\
\gamma_{\mathrm{S}}=\gamma_{\mathrm{S}}^{p}+\gamma_{\mathrm{S}}^{d}
\end{gathered}
$$

Where $\theta$ is the contact angles between steel and liquid, $\gamma_{\mathrm{L}}, \gamma_{\mathrm{L}}^{p}$ and $\gamma_{\mathrm{L}}^{d}$ is the surface tension, polar component and dispersion component of the testing liquid, respectively. $\gamma_{\mathrm{S}}, \gamma_{\mathrm{S}}^{p}$ and $\gamma_{\mathrm{S}}^{d}$ is the total surface energy, polar component and dispersion component of Q235 steel, respectively.

\subsection{FTIR}

A FTIR-8400S fourier transform infrared was used to measure the organic groups on Q235 steel surface at room temperature. The Q235 steel powder before and after treatment was mixed with $\mathrm{KBr}$ in the weight ratio of 1:100. Then, the mixture was pressed to a thin sheet under $80 \mathrm{MPa}$ for $2-5 \mathrm{~min}$. The scan range was $0-4000 \mathrm{~cm}^{-1}$.

\subsection{XPS}

Chemical bonding states of the fiber surface were investigated by X-ray photoelectron spectroscopy (XPS, AXISULTRA, Kratos, UK). XPS spectras were obtained with monochromatic 
Al $\mathrm{K}_{\alpha}(1486.71 \mathrm{eV})$ line at a power of $100 \mathrm{~W}(10 \mathrm{~mA}, 10 \mathrm{KV})$ with the vacuum about 10-8 Torr.. The charge neutralizer was used to compensate for surface charge effects, and binding energies were calibrated using the C1s hydrocarbon peak at $285 \mathrm{eV}$.

\subsection{AFM}

Atomic force microscopy (AFM, Dimension Icon) was used to observe and test the surface morphology and roughness of Q235 steel. The images with a $10 \mu \mathrm{m} \times 10 \mu \mathrm{m}$ scan area were obtained under tapping mode. Steel surface roughness was characterized by arithmetic mean roughness (Ra).

\section{Results and discussion}

\subsection{The adhesion}

Table 2 is adhesion strengths between epoxy coatings and Q235 steels. The adhesion strength of the control sample was only $1.67 \pm 0.48 \mathrm{MPa}$. After $2 \mathrm{~min}$ air plasma treatment, the adhesion strength was raised to $4.25 \pm 0.58 \mathrm{MPa}$, which was 1.75 times than that of the non-treatment.

Table 2. The adhesion strength between epoxy coatings and Q235 steel.

\begin{tabular}{cc}
\hline Sample & Adhesion (MPa) \\
\hline Control & $1.67 \pm 0.48$ \\
Air plasma treated & $4.25 \pm 0.58$ \\
\hline
\end{tabular}

The results indicated that air plasma treatment can effectively enhance the adhesion strength between epoxy coatings and metal matrix. There are several reasons for this phenomenon. First, the grease stains and dirt on steel surface can be removed by air plasma, which makes the surface cleaner than that of the untreated. Secondly, after air plasma treatment, the roughness of steel surface was improved through the slight etching. An increasing in the roughness results in more contact area and more mechanical interlocking between coatings and Q235 steels. Moreover, the large amounts of oxygen, nitrogen active groups were introduced on steel surface to improve the chemical active. All in all, the adhesion strengths between epoxy coatings and Q235 steel can be increased due to above reasons.

\subsection{AFM}

Figure 2 is the surface morphology of steel surface before and after treatment. Table 3 shows the surface roughness of steel. As shown in Figure 2, there was nothing except some neat scratches on surface of the control specimen. After air plasma treatment, a few small bulges were observed on steel surface. Meanwhile, the roughness of the treated steel was $37.71 \pm 1.11 \mathrm{~nm}$, double times than that of the untreated steel $(18.03 \pm 1.38 \mathrm{~nm})$. This indicates that air plasma treatment can effectively improve the surface roughness to increase the adhesion between coatings and steel matrix.

Table 3. The surface roughness of Q235 steel.

\begin{tabular}{ccccc}
\hline Sample & \multicolumn{3}{c}{ Ra roughness $(\mathrm{nm})$} & Average Ra roughness $(\mathrm{nm})$ \\
\hline Control & 16.82 & 19.57 & 17.63 & $18.03 \pm 1.38$ \\
Air plasma & 37.27 & 36.89 & 38.98 & $37.71 \pm 1.11$ \\
\hline
\end{tabular}

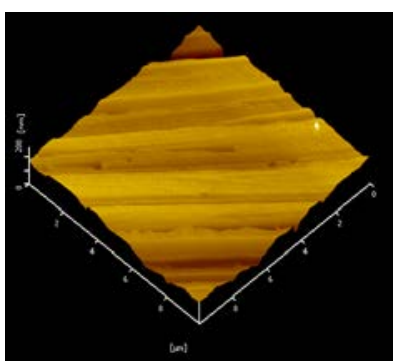

(a) control

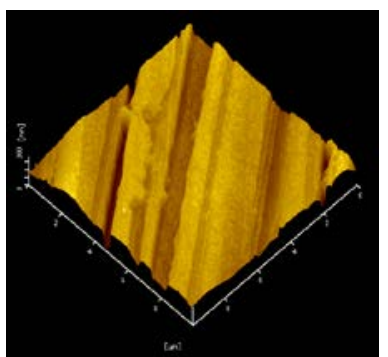

(b) air plasma treated.

Figure 2. Surface morphology of the polyamide 66 films; (a) control, (b) air plasma treated.

\subsection{FTIR}

The FTIR spectras of the Q235 steel powder before and after treated were shown in Figure 3. Compared with the spectra of the steel untreated, there was a wide peak appeared at $3641-3324 \mathrm{~cm}^{-1}$ 
of the steel after treated, which referred to the $-\mathrm{OH}$ group. The peaks at $1640 \mathrm{~cm}^{-1}$ and $1600 \mathrm{~cm}^{-1}$ (N-H group) were also increased after treated. It shows that after air plasma treatment, some polar groups, $-\mathrm{OH}$ and $-\mathrm{NH}_{2}$, were successful introduced on steel surface, making the adhesion strength improved.

\subsection{XPS}

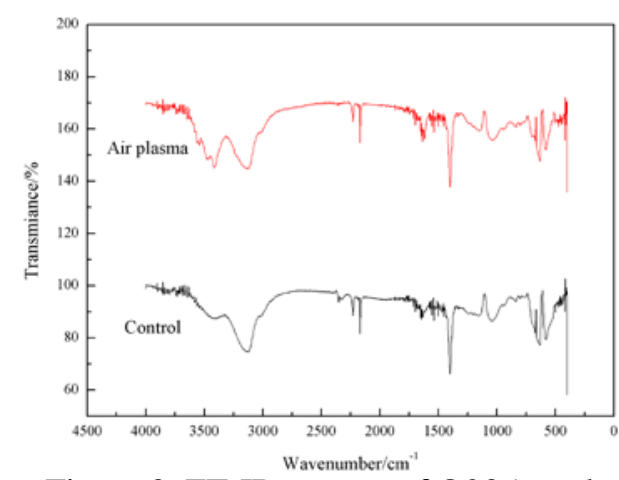

Figure 3. FT-IR spectra of Q235 steel.

Figure 4 is the XPS survey spectra of Q235 steel before and after treated. What can be seen from Figure 4 that there is few changes in the content of surface chemical element after air plasma treatment. Figure 5 shows the Fe2p (705-715 eV) high-resolution spectra of Q235 steel. The content of the functional groups was listed in Table 4.

Table 4.The functional groups on the Q235 steel.

\begin{tabular}{ccccc}
\hline Sample & $\begin{array}{c}\mathrm{Fe}-\mathrm{Fe} \\
(706.8 \mathrm{eV})\end{array}$ & $\begin{array}{c}\mathrm{Fe}-\mathrm{O} / \mathrm{Fe}(\mathrm{OH})_{2} \\
(708.6 \mathrm{eV})\end{array}$ & $\begin{array}{c}\mathrm{Fe}_{2} \mathrm{O}_{3} \\
(710.4 \mathrm{eV})\end{array}$ & $\begin{array}{c}\mathrm{FeOOH} \\
(711.6 \mathrm{eV})\end{array}$ \\
\hline Control & $9.7 \%$ & $61.4 \%$ & $11.8 \%$ & $17.1 \%$ \\
Air plasma treated & - & - & $45.1 \%$ & $54.9 \%$ \\
\hline
\end{tabular}

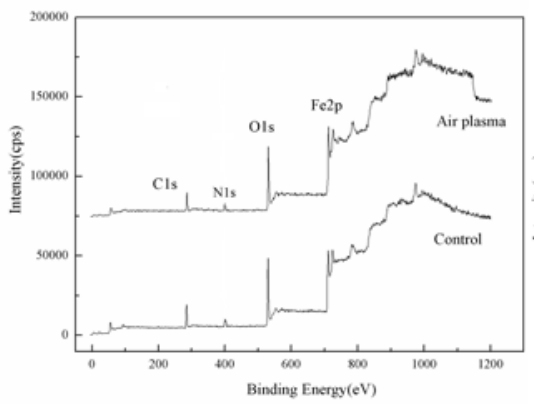

Figure 4. XPS survey spectra of the Q235 steel.

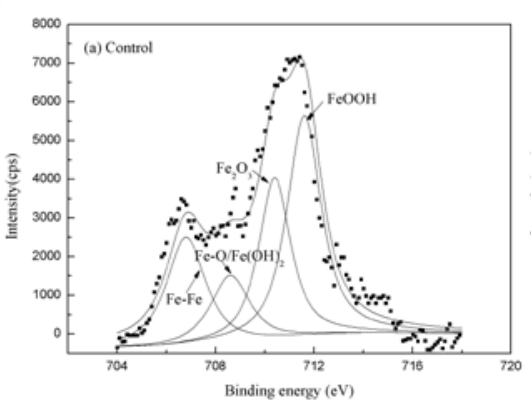

Figure 5 Fe2p high-resolution spectra of the Q235 steel;

(a) control, (b) air plasma treated.

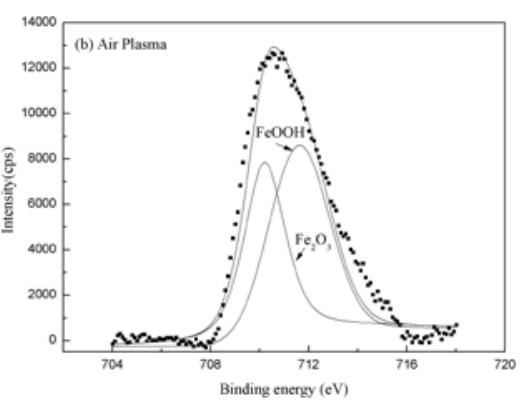

There were four types of Fe on the untreated steel surface, including Fe-Fe (706.8eV), $\mathrm{Fe}-\mathrm{O} / \mathrm{Fe}(\mathrm{OH})_{2}(708.6 \mathrm{eV}), \mathrm{Fe}_{2} \mathrm{O}_{3}(710.4 \mathrm{eV})$ and $\mathrm{FeOOH}(711.6 \mathrm{eV})$. After air plasma treatment, the surface of the steel only existed $\mathrm{Fe}_{2} \mathrm{O}_{3}$ and $\mathrm{FeOOH}$. It shows that before treatment, parts of Fe on surface has been oxidized. The main form of oxidation is $\mathrm{Fe}-\mathrm{O} / \mathrm{Fe}(\mathrm{OH})_{2}$. After air plasma treatment, all $\mathrm{Fe}$ on the surface was oxidized into $\mathrm{Fe}_{2} \mathrm{O}_{3}$ and $\mathrm{FeOOH}$. The content of FeOOH was higher than that of $\mathrm{Fe}_{2} \mathrm{O}_{3}$. Based on test results of adhesion strength and above conclusions, it indicates that the generated iron oxide $\mathrm{Fe}_{2} \mathrm{O}_{3}$ and $\mathrm{FeOOH}$ by air plasma treatment on the matrix surface can improve adhesion between coatings and metal matrix, and $\mathrm{FOOH}$ makes more contribution to improve coatings adhesion than $\mathrm{Fe}_{2} \mathrm{O}_{3}$. It is because that $\mathrm{FeOOH}$ has a higher content of -OH group on its surface, and forming more chemical bonds between coatings and metal matrix.

\subsection{Surface free energy}

Table 5 shows the calculation results of the surface free energy. The total surface free energy of the untreated steel was $41.25 \mathrm{~mJ} / \mathrm{m}^{2}$. While the polar and dispersive component of surface free energy were $19.14 \mathrm{~mJ} / \mathrm{m}^{2}$ and $22.11 \mathrm{~mJ} / \mathrm{m}^{2}$, respectively. The ration of the polar and dispersive component was 0.87 . After air plasma treatment, the total surface free energy was increased to 
$47.15 \mathrm{~mJ} / \mathrm{m}^{2}, 14.3 \%$ higher than that of the control. The ration of the polar and dispersive component was increased to $0.97,11.5 \%$ higher than that of the control. This is due to the fact that the air plasma treatment enhances the surface roughness and introduces some polar groups on steel surface.

Table 5. The surface free energy of the Q235 steel $\left(\mathrm{mJ} / \mathrm{m}^{2}\right)$.

\begin{tabular}{ccccc}
\hline Sample & $\gamma_{\mathrm{s}}^{\mathrm{p}}$ & $\gamma_{\mathrm{s}}^{\mathrm{d}}$ & $\gamma_{\mathrm{s}}$ & $\gamma_{\mathrm{s}}^{\mathrm{p}} / \gamma_{\mathrm{s}}^{\mathrm{d}}$ \\
\hline Control & 19.14 & 22.11 & 41.25 & 0.87 \\
Air plasma treated & 23.33 & 23.82 & 47.15 & 0.98 \\
\hline
\end{tabular}

\section{Conclusions}

In this work, Q235 steel was treated by the air plasma for 2 min at room temperature. After treatment, the roughness of the steel surface was improved from $18.03 \pm 1.38 \mathrm{~nm}$ to $37.71 \pm 1.11$ $\mathrm{nm}$ through the slight etching. Polar groups, -OH and -NH2, were introduced on steel surface. Meanwhile, some $\mathrm{FeOOH}$, with higher content of $-\mathrm{OH}$ group was generated on steel surface, forming more chemical bonds between the coating and metal matrix. In addition, the total surface free energy of Q235 steel was increased from $41.25 \mathrm{~mJ} / \mathrm{m} 2$ to $47.15 \mathrm{~mJ} / \mathrm{m} 2$. Base on the above changes in chemical and physical properties of the matrix surface, the adhesion strength between coatings and matrix was increased from $1.67 \pm 0.48 \mathrm{MPa}$ to $4.25 \pm 0.58 \mathrm{Mpa}$. It shows that the adhesion strength between epoxy coatings and Q235 steel can be effectively improved by the air plasma treatment.

\section{Acknowledgement}

The authors acknowledge financial support from the integrated project of Science and Technology of Shaanxi Province, China (No 2014SZ09-Z01); the project of Material Corrosion and Protection Key Laboratory of Sichuan Province (No.2014CL02); the Key Science-Technology Project of Shaanxi Province, China (No. 2014K08-38); Excellent Doctor Degree Dissertation Research Foundation of Xi'an University of Technology; Key Laboratory Project of Education department of shaanxi province: The preparation of epoxy coatings by plasma spraying.

\section{References}

[1] H. Yun, J. Li, H.B. Chen, C.J. Lin. A study on the $\mathrm{N}^{-}, \mathrm{S}^{-}$and $\mathrm{Cl}^{-}$modified nano- $\mathrm{TiO}_{2}$ coatings for corrosion protection of stainless steel. Electrochimica Acta, 2007, 52(24):6679-6685.

[2] Z. Zhai, L.J. Feng, Z. Liu, S.S. Zhou, H. Lou, G.Z. Li. Water absorption and mechanical property of an epoxy composite coating containing unoxidized aluminum particles. Progress in Organic Coatings, 2015, 87:106-111.

[3] E.O. Eltai, J.D. Scantlebury, E.V. Koroleva. The effects of zinc ions on the performance of epoxy coated mild steel under cathodic protection (CP). Progress in Organic Coatings, 2013, 76(4):548-554.

[4] T.T.X. Hang, N.T. Duong, T.A. Truc, T. Hoang, D.T.M. Thanh, S. Daopiset, A. Boonplean. Effects of hydrotalcite intercalated with corrosion inhibitor on cathodic disbonding of epoxy coatings. Journal of Coatings Technology \& Research, 2015, 12(2):1-9.

[5] Z. Wang, E. Han, F. Liu, Z. Qian, L. Zhu. Waterborne Epoxy Nanocoatings Modified by Nanoemulsions and Nanoparticles. Journal of Materials Science \& Technology, 2014, 30(10):1036-1042.

[6] H.W. Shi, F.C. Liu, E.H. Han. Surface-engineered Microcapsules by Layer-by-layer 
Assembling for Entrapment of Corrosion Inhibitor. Journal of Materials Science \& Technology, 2015, 31(5):512-516.

[7] G.Z. Li, L.J. Feng, P.R. Tong, Z. Zhai. The properties of MWCNT/polyurethane conductive composite coating prepared by electrostatic spraying. Progress in Organic Coatings, 2016,

[8] S.J. Park, B. J. Kim. Influence of oxygen plasma treatment on hydrogen chloride removal of activated carbon fibers. Journal of Colloid \& Interface Science, 2004, 275(2):590-5.

[9] Z. Zhai, Z. Liu, L.J. Feng, S. Liu. Interfacial adhesion of glass fibre reinforced polypropylene-maleic anhydride modified polypropylene copolymer composites. Journal of Reinforced Plastics \& Composites, 2014, 33(8):785-793. 